\title{
The Patient's Satisfaction and Influencing Factors in Remote Consultation
}

\author{
Wei Lu", Dongxu Sun ${ }^{2, *}$ \\ ${ }^{1}$ School of Management Engineering, Zhengzhou University, Science Avenue, Zhengzhou, China \\ ${ }^{2}$ The First Affiliated Hospital of Zhengzhou University, Zhengzhou University, Zhengzhou, China
}

973984435@qq.com

Keywords: remote consultation, the patient's satisfaction, influencing factors, mediating effect

\begin{abstract}
Based on the present research and the patient 's trust as the mediator, this paper discusses the relationship between the personnel quality perception, procedural quality perception, technical quality perception, tariff perception and the patient's satisfaction in the background of the development of telemedicine in Henan province. The results show that: personnel quality perception, procedural quality perception, technical quality perception and fee perception have a significant positive impact on patient's satisfaction. Personnel quality perception and procedural quality perception have a greater impact on patient's satisfaction, meanwhile, the patient's trust plays an intermediary role.
\end{abstract}

\section{Introduction}

Remote consultation using modern communication technology to expand the medical treatment and medical information (Jie Zhao, 2014), and then achieve the advantages of sharing resources to improve the patient cure effect. Remote Consultation is recognized by patients and professionals because of its higher accessibility, quality, efficiency and effectiveness, especially by overcoming the distance and time constraints between doctors and patients, greatly assisting areas where traditional service levels are inadequate (Nouhi M, 2012).

patient's satisfaction is an important measure of hospital treatment results and medical service quality, is an important means to improve the quality of medical services improvement (Sen Huang, 2012), can objectively reflect the quality of medical services is good or bad.The difference in the quality of medical service and patient's satisfaction determines the quality of service is a key factor in improving patient's satisfaction (Choi KS, 2004. Lei P, 2013).

However, telemedicine as a new part of the hospital organization, there are many immature and even failure of the practices and models in the implementation process, the management system, especially the quality management system is not perfect, there is no effective quality management system to guide the quality of remote consultation, which led to reduced patient's satisfaction, and how to improve patient's satisfaction, as the government, hospitals and academia continue to study the subject.

\section{Theoretical Review and Research Hypothesis}

\subsection{Personnel Quality Perception}

Personnel quality perception is the perception of the quality of the service provider (including the donor, the recipient, and the staff in the consultation) during the remote consultation process.

Personnel quality perception is the perception of the quality of the service provider (including the donor, the recipient, and the staff in the consultation) during the remote consultation process. Xiaoling Ruan, et al (Xiaoling Ruan, 2012), discussed the impact of quality service on patient's satisfaction. The results showed that the satisfaction rate was $70 \%$ before the implementation of quality nursing service. After the implementation of quality nursing service, the satisfaction rate of patients was significantly improved, $96 \%$, indicating that quality care interventions can improve the quality of service and greatly improve patient's satisfaction. Xiangyu Liu, et al(Xiangyu Liu, 
2015), constructed a service satisfaction evaluation index system, and empirical research shows that the patient's perception of the impact of personnel services on its satisfaction, the better the patient's perception of service quality, the greater the degree of expectation, the higher the patient's satisfaction. Accordingly, this paper makes the following assumption:

H1: At the time of remote consultation, there is a significant positive correlation between personnel quality perception and patient's satisfaction.

\subsection{Procedural Quality Perception}

Procedural quality perception is the patient's perception of the fluency of the entire consultation process. Yuan He et al(Yuan He, 2009), studied the management and satisfaction of logistics equipment in a hospital in Shanghai, and put forward that the effective and effective process management can improve the logistics efficiency, management and customer satisfaction to a large extent. Li'e $\mathrm{Li}$, et al(Lie $\mathrm{Li}, 2016)$, explored the effect of fine process management in the management of nursing rooms in the operating room. In the control group, routine management was used in the control group. The observation group was treated with fine process management. The overall satisfaction rate of the observation group was $97.5 \%$, the quality score was $100.74 \pm 3.1$, which was significantly higher than the control group of $85.0 \%$ and $52.32 \pm 2.45$ points, so the refinement of the process management will help improve the operating room care management satisfaction and quality. Accordingly, this paper makes the following assumption:

H2: At the time of remote consultation, there is a significant positive correlation between procedural quality perception and patient's satisfaction.

\subsection{Technical Quality Perception}

Technical quality perception is the perception of the consultation technique in the process of remote consultation. High level of technical quality is not only to ensure that patients are satisfied with the core, it is the hospital recognized by the community (Jianwei Ji, 2013). Lei Xia, et al (Lei Xia, 2015), analyzed the patient's satisfaction, explored the influencing factors, and ultimately determine the impact of the larger seven factors, the technical level is the primary influencing factor, can improve the technical level to improve the patient's satisfaction. Accordingly, this paper makes the following assumption:

H3: At the time of remote consultation, there is a significant positive correlation between technical quality perception and patient's satisfaction.

\subsection{Fee Perception}

Fee perception is perceived by patients on remote consultation fees. Haibo, Qi, et al (Haibo Qi, 2012), in order to understand the patient's medical expenses on the hospital medical behavior satisfaction in the city launched a sample survey to investigate the medical expenses on the medical results of the satisfaction of the situation, reasonable medical costs are conducive to the harmonious development of doctor-patient relationship, then improving the quality of medical services and patient's satisfaction. Ming-mei Fu and Yajuan Dong (Mingmei Fu, 2014) used the meta-analysis method to explore the relationship of hospitalization time, cost and satisfaction, results show that we can reduce the cost to improve patient's satisfaction. Accordingly, this paper makes the following assumption:

H4: At the time of remote consultation, there is a significant positive correlation between fee perception and patient's satisfaction.

\subsection{The Mediating Role of Patient's Trust}

Trust is the subjective feelings of the people, when the service provider to show customers good quality, effect, reputation and other positive performance, will allow customers can not help but trust or even trust. Hong et al(Hong, 2013), studied the online shopping scenario and found that trust affected consumer behavior to a large extent and showed a significant positive correlation. Accordingly, this paper makes the following assumption:

$\mathrm{H} 5$ : At the time of consultation, there is a significant positive correlation between trust and patient's satisfaction.

H6a: At the time of consultation, patient's trust plays a mediating role in the personnel quality perception and patient's satisfaction. 
H6b: At the time of consultation, patient's trust plays a mediating role in the procedural quality perception and patient's satisfaction.

H6c: At the time of consultation, patient's trust plays a mediating role in the technical quality perception and patient's satisfaction.

H6d: At the time of consultation, patient's trust plays a mediating role in the fee perception and patient's satisfaction.

\section{METHOD}

\subsection{Data Sources}

March - June, 2017, this group conducted a survey on the quality of telemedicine services in remote medical sub-centers and county-level telemedicine centers on site. The survey was conducted in an anonymous manner and the subjects were patients who had received a remote consultation service.

\subsection{Research Model and Scale}

Combined with the existing hypothesis, the conceptual model of the influencing factors of patient satisfaction in this paper is shown in Figure1. The definition and measurement of each variable are shown in Table 1.

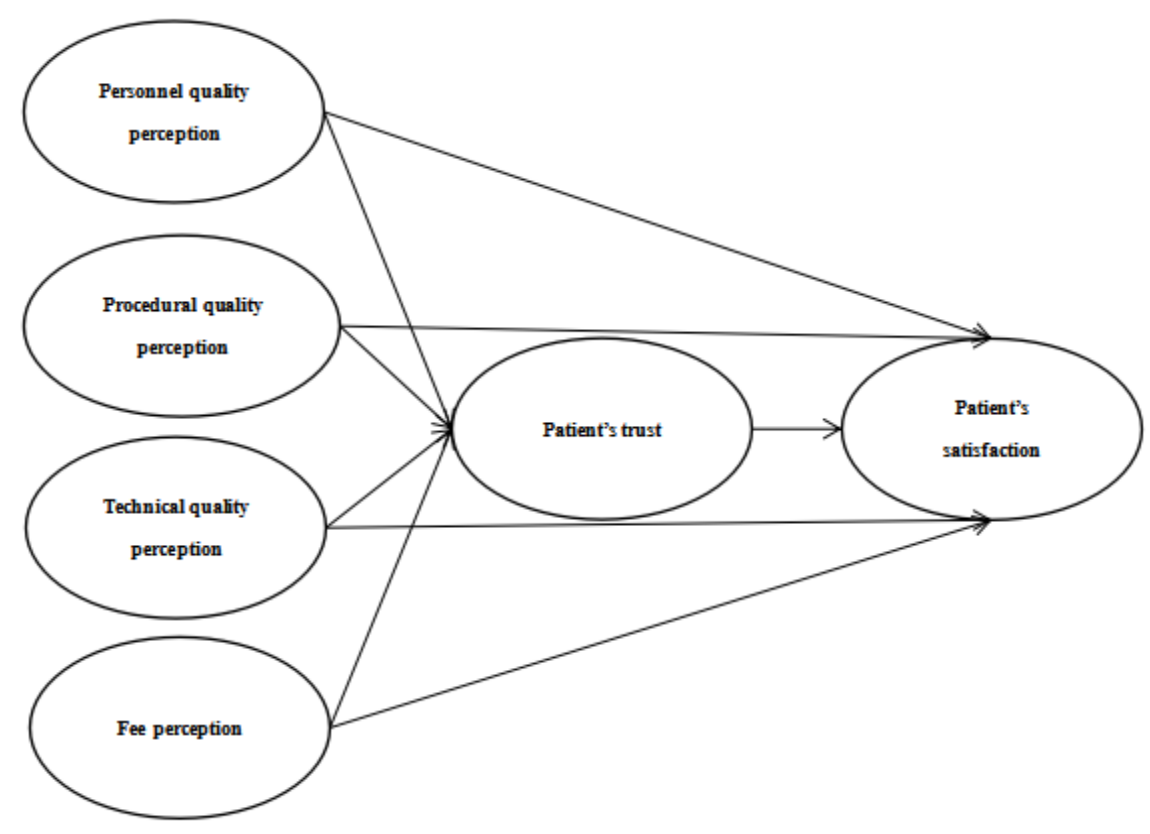

Figure 1: This research conceptual model.

\section{Data analysis}

\subsection{Descriptive Statistical Analysis}

A total of 706 questionnaires were collected and all the same options were removed. The effective questionnaires were 446 valid and the effective recovery rate was $63.2 \%$. The basic information of the survey is shown in Table 2.

\subsection{Pearson Correlation Coefficient}

The correlation coefficient between the calculated item and the total score of the scale is less than 0.05 , the correlation coefficient is more than 0.3 , so the correlation coefficient method does not delete the entry, the results shown in Table1.

\subsection{Reliability and Validity Test}

\subsubsection{Reliability Test}

It is generally believed that a good reliability coefficient of the scale, the reliability coefficient of the best in more than 0.8, the sub-table is best in more than 0.7(Abd-EI-Fattah, 2010).Reliability analysis results in Table 1, the scale showed a higher level of reliability, so the scale has a very high 
intrinsic consistency, reliability is strong.

Table 1: The correlation coefficient of the scale.

\begin{tabular}{|c|c|c|c|c|}
\hline Scale & Pearson & Cronbach’s Alpha & Standardized factor load & CR \\
\hline $\begin{array}{l}\text { Personnel quality } \\
\text { perception (A) }\end{array}$ & $\begin{array}{l}0.808 \\
0.751 \\
0.725 \\
0.739 \\
0.694 \\
0.721 \\
0.732 \\
0.837 \\
0.393 \\
\end{array}$ & 0.908 & $\begin{array}{l}0.80 \\
0.70 \\
0.72 \\
0.68 \\
0.70 \\
\\
0.84 \\
0.63\end{array}$ & 0.895 \\
\hline $\begin{array}{l}\text { Procedural quality } \\
\text { perception (B) }\end{array}$ & $\begin{array}{l}0.773 \\
0.793 \\
0.716 \\
0.744 \\
0.782 \\
0.804 \\
0.797\end{array}$ & 0.925 & $\begin{array}{l}0.75 \\
0.79 \\
0.69 \\
0.73 \\
0.77 \\
0.60 \\
0.79\end{array}$ & 0.907 \\
\hline $\begin{array}{l}\text { technical quality } \\
\text { perception (C) }\end{array}$ & $\begin{array}{l}0.805 \\
0.830 \\
0.807 \\
0.825 \\
0.812 \\
0.828 \\
0.753 \\
0.709\end{array}$ & 0.944 & $\begin{array}{l}0.80 \\
0.83 \\
0.92 \\
0.83 \\
0.83 \\
0.84 \\
0.74\end{array}$ & 0.921 \\
\hline fee perception (D) & $\begin{array}{l}0.719 \\
0.601 \\
0.645 \\
\end{array}$ & 0.759 & $\begin{array}{l}0.74 \\
0.58 \\
0.61 \\
\end{array}$ & 0.884 \\
\hline Patient’s trust(T) & $\begin{array}{l}0.692 \\
0.732\end{array}$ & 0.875 & $\begin{array}{l}0.67 \\
0.71\end{array}$ & 0.916 \\
\hline $\begin{array}{l}\text { Patient's satisfaction } \\
\text { (S) }\end{array}$ & $\begin{array}{l}0.720 \\
0.734 \\
0.803\end{array}$ & 0.973 & $\begin{array}{l}0.729 \\
0.654 \\
0.782\end{array}$ & 0.923 \\
\hline
\end{tabular}

Table 2: The demographic characteristics of respondents.

\begin{tabular}{|c|c|c|c|}
\hline General characteristics & Classification & Number (person) & Ratio (\%) \\
\hline \multirow{2}{*}{ Sex } & Male & 222 & 49.8 \\
\hline & Female & 224 & 50.2 \\
\hline \multirow{4}{*}{ Age } & $\leq 20$ & 3 & 0.7 \\
\hline & $20 \sim 40$ & 172 & 38.5 \\
\hline & $40 \sim 60$ & 169 & 37.9 \\
\hline & $>60$ & 102 & 22.9 \\
\hline \multirow{2}{*}{ Census } & Town & 198 & 44.4 \\
\hline & Rural & 248 & 55.6 \\
\hline \multirow{3}{*}{ Degree } & $\begin{array}{l}\text { Junior high school and } \\
\text { below }\end{array}$ & 193 & 43.3 \\
\hline & High school and college & 195 & 43.7 \\
\hline & Undergraduate and above & 58 & 13.0 \\
\hline
\end{tabular}

4.3.2 Validity Test

In this paper, factorial analysis is used to test the structural validity of the scale. Before the validity of the test, the KMO and Bartlett spherical tests are used to determine whether the data is 
suitable for factor analysis. After analysis, the total KMO of the sample is 0.965 , and the significance probability $\mathrm{P}$ of the Bartlett spherical test is $0.000<0.05$, which indicates that there is a correlation between the variables and is suitable for factor analysis.

SPSS21.0 was used to analyze the validity of the scale by using the principal factor analysis method to explore the validity of the scale. The main factor with the eigenvalue of more than 1 was extracted and the factor rotation was carried out by the maximum variance orthogonal rotation method to form the rotation component matrix, which part of the factor load is 0.5 or less, should be deleted. Then, all the factor factor load are more than 0.5 , said the scale has a good validity.

And then continue to expand the confirmatory factor analysis, the results shown in Table 3 . The main indexes CMIN / DF, GFI, CFI, and RMSEA are 5.016, 0.826, 0.899 and 0.095, respectively. The results show that the model is not good. When the sample size is large (usually greater than 150 is a large sample), $\mathrm{P}$ value can not be used as a fitting index (Abd-EI-Fattah, 2010), we need to modify the index, critical ratio and path analysis of the model to be amended. The corrected squareness of the model is obviously reduced, CMIN / DF is less than 5, GFI and CFI are more than 0.9, RMSEA is less than 0.08, indicating that the modified model is ideal, and the AVE of each variable is above 0.5 Table 3 ), indicating that the scale of convergence is better, AVE square root is greater than the scale and other scale correlation coefficient, indicating that there are significant differences between the latent variables.

\section{Hypothetical test}

Regression analysis results are shown in Table 4. According to Model1-1, the personnel quality perception has a significant positive impact on patient's satisfaction $(\beta=0.85, \mathrm{P}<0.001)$, so $\mathrm{H} 1$ is established. From Model1-3, it was found that personnel quality perception also has a significant positive effect on patient's trust $(\beta=0.85, \mathrm{P}<0.001)$, so $\mathrm{H} 2$ is established. From Model2-3, it was found that procedural quality perception also had a significant positive effect on patient's trust ( $\beta=0.87, \mathrm{P}<0.001)$.Compared with Model1-2 and Moedl1-1 and Moedl2-2 and Model2-1, it can be seen that the regression equation is significantly improved after adding the patient's trust into the regression equation (Model1: $\triangle \mathrm{R}^{2}=0.079, \mathrm{P}<0.05$; Model2: $\triangle \mathrm{R}^{2}=0.082, \mathrm{P}<0.05$ ). The impact of personnel quality perception and procedural quality perception on patient's satisfaction was significantly reduced, but it also maintained a positive effect, which suggests that patient's trust plays a mediating role in the relationship between patient's satisfaction and personnel quality perception, and patient's satisfaction and procedural quality perception. Therefore, it is assumed that H6a and H6b are established.

Table 3: Convergence validity and discriminant validity test.

\begin{tabular}{|c|c|c|c|c|c|c|c|}
\hline & AVE & 1 & 2 & 3 & 4 & 5 & 6 \\
\hline A & 0.705 & 0.84 & & & & & \\
\hline B & 0.725 & 0.74 & 0.85 & & & & \\
\hline C & 0.734 & 0.74 & 0.67 & 0.86 & & & \\
\hline D & 0.711 & 0.30 & 0.28 & 0.26 & 0.84 & & \\
\hline T & 0.654 & 0.70 & 0.71 & 0.57 & 0.41 & 0.81 & \\
\hline S & 0.744 & 0.85 & 0.54 & 0.43 & 0.33 & 0.66 & 0.86 \\
\hline
\end{tabular}

It is known from Model3-1 that technical quality perception has a significant positive effect on patient's satisfaction $(\beta=0.43, \mathrm{P}<0.001)$, assuming that $\mathrm{H} 3$ is established. It is known from Model33 that technical quality perception also has a significant positive effect on patient's trust $(\beta=0.48, P$ $<0.001)$. It is known from Model4-1 that the fee perception has a significant positive effect on patient's satisfaction $(\beta=0.33, \mathrm{P}<0.001)$, assuming that $\mathrm{H} 4$ is established. Compared with Model3-2 and Moedl4-2 and Moedl4-2 and Model4-1, it can be seen that the regression equation is significantly improved after adding the patient's trust into the regression equation (Model3: $\triangle$ $\mathrm{R}^{2}=0.024, \mathrm{P}<0.05$; Model4: $\triangle \mathrm{R}^{2}=0.015, \mathrm{P}<0.05$ ). The impact of technical quality perception and fee perception on patient's satisfaction was significantly reduced, but it also maintained a positive 
effect, which suggests that patient's trust plays a mediating role in the relationship between patient's satisfaction and technical quality perception, and patient's satisfaction and fee perception. Therefore, it is assumed that H6c and H6d are established. At the same time, it was found by four models that patient's trust had a significant positive effect on patient's satisfaction, so it was assumed that $\mathrm{H} 5$ was established.

Table 4: The mediator effect test of patient's trust.

\begin{tabular}{|c|c|c|c|c|c|c|}
\hline $\begin{array}{c}\text { Dependent } \\
\text { variable }\end{array}$ & $\begin{array}{l}\text { Model1-1 } \\
\text { satisfaction }\end{array}$ & $\begin{array}{l}\text { Model1-2 } \\
\text { satisfaction }\end{array}$ & $\begin{array}{c}\text { Model1-3 } \\
\text { trust }\end{array}$ & $\begin{array}{l}\text { Model2-1 } \\
\text { satisfaction }\end{array}$ & $\begin{array}{l}\text { Model2-2 } \\
\text { satisfaction }\end{array}$ & $\begin{array}{c}\text { Model 2-3 } \\
\text { trust }\end{array}$ \\
\hline A & $\begin{array}{l}0.85 \\
* * *\end{array}$ & $\begin{array}{l}0.35 \\
* * *\end{array}$ & $\begin{array}{l}0.66 \\
* * *\end{array}$ & & & \\
\hline B & & & & $\begin{array}{l}0.54 \\
* * *\end{array}$ & $\begin{array}{l}0.43 \\
* * *\end{array}$ & $\begin{array}{l}0.87 \\
* * *\end{array}$ \\
\hline $\mathrm{T}$ & & $\begin{array}{l}0.94 \\
* * *\end{array}$ & & & $\begin{array}{l}0.67 \\
* * *\end{array}$ & \\
\hline R2 & 0.235 & 0.314 & 0.253 & 0.203 & 0.285 & 0.225 \\
\hline$\triangle \mathrm{R}^{2}$ & & 0.079 & & & 0.082 & \\
\hline $\begin{array}{c}\text { Dependent } \\
\text { variable }\end{array}$ & $\begin{array}{c}\text { Model3-1 } \\
\text { satisfaction }\end{array}$ & $\begin{array}{c}\text { Model3-2 } \\
\text { satisfaction }\end{array}$ & $\begin{array}{c}\text { Model3-3 } \\
\text { trust }\end{array}$ & $\begin{array}{c}\text { Model4-1 } \\
\text { satisfaction }\end{array}$ & $\begin{array}{c}\text { Model4-2 } \\
\text { satisfaction }\end{array}$ & $\begin{array}{c}\text { Model 4-3 } \\
\text { trust }\end{array}$ \\
\hline $\mathrm{C}$ & $\begin{array}{l}0.43 \\
* * *\end{array}$ & $\begin{array}{l}0.35 \\
* * *\end{array}$ & $\begin{array}{l}0.48 \\
* * *\end{array}$ & & & \\
\hline $\mathrm{D}$ & & & & $\begin{array}{l}0.33 \\
* * *\end{array}$ & $\begin{array}{l}0.21 \\
* * *\end{array}$ & $\begin{array}{l}0.45 \\
* * *\end{array}$ \\
\hline $\mathrm{T}$ & & $\begin{array}{l}0.64 \\
* * *\end{array}$ & & & $\begin{array}{l}0.74 \\
* * *\end{array}$ & \\
\hline R2 & 0.063 & 0.087 & 0.103 & 0.061 & 0.076 & 0.125 \\
\hline$\triangle \mathrm{R}^{2}$ & & 0.024 & & & 0.015 & \\
\hline
\end{tabular}

\section{Summary and Suggestion}

This paper has carried on the empirical research to the mechanism of the remote perception. The study found that personnel quality perception, procedural quality perception, technical quality perception and fee perception have a significant positive impact on patient satisfaction, and they all affect the patient's attitude towards teleconference, patient's trust in patient perception and Patient's satisfaction plays an intermediary role in the middle. On the other hand, among the patient's perceived, the personnel quality perception and the procedural quality perception have greater impact on the patient's satisfaction, so as a starting point to improve the remote consultation in patients with satisfaction several recommendations:

(1)Strengthen the construction of qualified personnel, improve the efficiency of consultation

Strengthen the construction of telemedicine personnel to ensure the efficient implementation of consultation. Strengthen the staff's business skills training, pay attention to pre-job training and continuing education, improving the staff's business skills training, updating and assessment, improve staff business skills; improving the eligibility system, strengthen the quality control of employees to ensure the successful and efficient operation of the consultation.

The comprehensive quality of the experts is to ensure the smooth development of the key(Xiao Han, 2010).Remote consultation, because it is through the machinery and equipment with the distant hospital to communicate, and even patients cannot participate in the whole process, the patient cannot contact with the doctor face to face, which make them have no sense of security and resistance, and remote consultation overall time is short relatively, so that patients feel that the doctor is not responsible, did not take seriously their condition, did not get a reliable conclusion, which contradicts the remote consultation, which will affect the quality of remote consultation from the root, directly lead to poor user experience. Therefore, if you want to better serve patients, 
improve patient satisfaction, the hospital should be selected quality comprehensive, responsible experts to form a consultation group, improve the access system, to ensure the quality of consultation.

(2)Strengthen the standardization of process management, improve the quality of consultation

Remote consultation involves a number of links, any one part of the problem will affect the normal consultation, which requires the strengthening and standardization of consultation management process, the establishment of a reasonable standardized consultation process to ensure the orderly conduct of consultation. At the same time, the consultation makes the patient's information for the second transmission, making the patient have a conflict, which requires the standardization of consultation management process, the relevant personnel strictly follow the consultation process, to strengthen the confidentiality of patient information, eliminate patient concerns.

Practical consultation system and scientific and effective consultation process is the quality of consultation to control the effective protection and support. According to the national distribution of the unified consultation process, the hospital can be combined with the actual basis of the hospital on the consultation process for reasonable and effective regulation and control, with the formation of the hospital and even the characteristics of the region's effective remote consultation process, strictly follow the consultation process, control the quality of each link to protect the vital interests of patients, thereby improving patient satisfaction.

(3)Enhance patient trust, improve patient satisfaction

Public awareness of telemedicine is an effective guarantee for the sustainable development of telemedicine (Yunkai Zhai, 2016). Telemedicine relies on advanced technical means to serve patients(Xinyang Gong, 2015), with many advantages in terms of time, place and effect, and once the patients understand the benefits of the teleconference, the patient's needs and motivation will be further increase, while promoting the healthy development of telemedicine. Emphasizing the role of patients in the remote consultation constantly, paying attention to the remote consultation on the patient's publicity, improve social awareness, enhance patient confidence, so that they are willing and believe in distance medical consultation.

David Bowenand Benjamin Schneider found that there is a "satisfactory image" effect between the customer and the employee (Bowen, 1985), so that there is a significant positive impact between the service experience and the customer's emotions, a good service experience, the relationship between the patient and the patient, Will greatly enhance patient confidence, so that patients have a trust and dependence, thereby improving patient satisfaction.

\section{Acknowledgements}

This research is supported by National Natural Science Foundation of China- Influential Factors and Evaluation Model of Telemedicine Quality in Big Data Environment (Grant No. 71673254). The authors would like to thank the editors and anonymous referees for their careful and fruitful comments to improve the quality of this paper.

\section{References}

[1] Abd-EI-Fattah, Sabry, M, 2010. .Structural Equation Modeling with AMOS: Basic Concepts, Applications, and Programming, Journal of Applied Quantitative Methods. 2(5), pp.365-367.

[2] Bowen, D, Benjamin, S, 1985. Boundary-Spanning Role Employees and the Service Encounter:Some Guidelines for Management Research, The Service Industries Journal. 8(5), pp.47127.

[3] Choi, KS, Cho, WH, Lee, S, et al,2004. The Relationships Among Quality,Value,Satisfaction and Behavioral Intention in Health Care Provider Choice:A South Korean Study, Journal of Business Research. 57(8), pp.913-921.

[4] Haibo, Qi, Xiping, Jia, Chunmei, Ma, 2012. Investigation on Medical Expenses and Satisfaction 
of Medical Patients in Hospitalized Patients in Pingliang City, Medicine and Society. 25(06), pp.6063.

[5] Hong, I B, Cha, H S, 2013. The Mediating Role of Consumer Trust in an Online Merchant in Predicting Purchase Intention, International Journal of Information Management. 33(33), pp. 927939.

[6] Jianwei Ji, Dong, Zhou, Bingxi, Chen, 2013. The Path Choice and Thinking of Continuous Improvement of Medical Quality, Chinese Hospital Management. 33(12), pp.61-62.

[7] Jie, Zhao, Cai, Yanling, Dongxu, Sun, et al, 2014.The Current Situation and Future Trend of Telemedicine, Chinese Health Service Management. 4(10), pp.739-740.

[8] Lei, Li, Lichun, Ma, Yi, Ai, et al, 2015. Satisfaction Analysis and Evaluation of 652 Hospitalized Patients, Chinese Hospital Management. 35(02), pp.59-61.

[9] Lei, P, Jolibert, A, 2013. A Three-Model Comparison of the Relationship between Quality, Satisfaction and Loyalty: An Empirical Study of the Chinese Healthcare System, BMC Health Services Research. 12(1), pp.436.

[10] Lie, Li, Dongxia, Wang, Dandan, Zhu, 2016. Effects of Fine Process Management on Nursing Management Efficiency and Patient Satisfaction in Operating Room, Hainan Medical Journal. 27(21), pp.3597-3599.

[11] Mingmei, Fu, Yajuan, Dong, 2014. Meta-analysis of the Effect of Nursing Clinical Path on Hospitalization Time, Cost and Satisfaction of Depressed Patients, Mod Med J. 42(01), pp.65-69.

[12] Nouhi, M, Fayaz-Bakhsh, A, Mohamadi, E, et al, 2012. Telemedicine and Its Potential Impacts on Reducing Inequalities in Access to Health Manpower, Telemedicine and E-Health. 18(8), pp.648-653.

[13] Sen, Huang, Zhi, Song,Tuohong, Zhang, et al, 2012. Reliability and Validity Evaluation of Inpatients' Experience and Satisfaction Scale in Chinese Hospital, Chinese Hospital Management. 6(32), pp.14-17.

[14] Xiangyu, Liu, Yongyi, Zhan, Yujuan, Zhou, et al, 2015.Construction of Evaluation Index System of Nursing Service Satisfaction in Hospitalized Patients, Chin J Nurs. 50(01), pp.18-21.

[15] Xiao, Han, Wei, Wang, 2010. How to Ensure the Quality of Telemedicine Consultation, Journal of Medical Informatics. 23(8), pp.2554-2556.

[16] Xiaoling, Ruan, Yu, Qiu, Jianping, Huang, 2012. Effect of Quality Nursing Service on Patient Satisfaction of Pediatric Clinic, Contemporary Medicine. 18(15), pp.122-124.

[17] Xinyang, Gong, Ting, Su, Kun, Yang, et al, 2015. Research on the Current Situation of Telemedicine Development in China, Chinese Health Service Management.12(2), pp.160-164.

[18] Yuan, He, Minhua, Xu, Di, Xue, et al, 2009. Logistics Process Management and Satisfaction Analysis of Medical Devices in Shanghai, Chinese Hospital Management. 29(04), pp.26-28.

[19] Yunkai, Zhai, 2016. Analysis on the Mechanism of Telemedicine Promoting Medical Control Fee, Chinese Health Service Management. 6(5), pp.326-329. 